\title{
Evaluation of Double-sampling Estimators of Subalpine Herbage Production
}

\author{
GARY A. REESE, ROBERT L. BAYN, AND NEIL E. WEST
}

\begin{abstract}
Electronic capacitance metering, relative and dry weight estimations, and canopy cover estimation of herbaceous standing crops were statistically evaluated with respect to sampling costs, precisions, and the vegetal and environmental factors which affected their double-sampling correlations. Twenty-four factors were investigated using stepwise regression analysis. Minimum sampling costs were achieved when the double-sampling estimator technique was compatible with the characteristics of the sampling site. Relative and dry weight estimations were found to be consistently precise estimators in meadow, aspen, fir, and spruce-fir, and spruce-fir vegetation types. Both were successfully used by workers with no prior experience or training. The sampling techniques were capable of providing, at equal sampling cost, up to a 4-fold increase in sample size over that of clipping along, depending on the vegetation type.
\end{abstract}

The need for an inexpensive and precise estimator of herbage yield has become a classic topic in the range literature. A great deal of attention has been paid to the subject, primarily because of the difficulty in adequately sampling the highly variable standing crops encountered in many vegetation types. Since harvesting herbage is expensive and destructive, a technique which uses a large sample of acceptably lower precision estimates is generally better than a small sample of precise clipped measurements. The statistical parameters obtained with an estimator, however, must not be biased (Haydock and Shaw 1975) and the sample must also be less expensive to obtain than clipping, at equal levels of precision (Green 1949).

A varicty of both direct and indirect estimation techniques have been proposed which use a doublesampling with regression procedure (Cochran 1977) to minimize bias. While most of the techniques have been tested in the field, an uncertainty in how they compare with respect to cost, precision, and the factors influencing their performance, have made it difficult to choose the most efficient technique in a given sampling situation. The need for analysis of the factors influencing the precision of various double-sampling estimators has been recognized by several authors (Morley et al. 1964; Bryant et al. 1971; and Michalk and Herbert 1977). Jones et al. (1977) recently investigated the effects of tropical grassland composition on

\footnotetext{
The authors are former graduate research assistant, former research technician and professor, respectively, Department of Range Science, Utah State University, Logan, Utah 84322. Reese is now ecologist, Division of Energy, Missouri Department of Natural Resources, Jefferson City. Bayn is now research technician, Department of Biology, Utah State University.

This research was supported by National Science Foundation Grant DEB 75-13966 to James A. MacMahon and Utah Agr. Exp. Sta. Project 766. Submitted as Utah Agr. Exp. Sta. Journal Paper 2272. The authors wish to thank Mr. K.P. Haydock, C.S.I.R.O., Div. of Mathematics and Statistics, Cunningham Laboratory, St. Lucia, Queensland and Dr. Walter F. Mueggler, U.S.D.A., Forest Serv., Forestry Sciences Laboratory, Logan, Utah, for their critical comments on the manuscript. Debbie Ketchie, Susan Kadlec, and Marilyn Pratt assisted with field work.
}

electronic capacitance metering. However, similar regression studies on other double-sampling estimators are lacking.

The major objective in this study was to investigate the relationships between electronic capacitance metering (Neal et al. 1976; Jones et al. 1977) dry (Tadmor et al. 1975) and relative (Haydock and Shaw 1975) weight estimations, and canopy cover estimation (Payne 1974) in predicting subalpine herbage yields. Of specific interest was the statistical determination, through stepwise regression analysis, of which vegetal and environmental factors were responsible for reducing their sampling precision. The comparative costs of sampling with each of these estimators were also examined.

\section{Methods}

The study site was located at the $2,580 \mathrm{~m}(8,470 \mathrm{ft})$ elevation in the Bear River Range of northern Utah, approximately $40 \mathrm{~km}(25$ m) northeast of Logan, Utah. Four common vegetation types in the lower subalpine zone were selected in order to compare sampling techniques among vegetation types. These types included dry meadows and understory vegetation of adjacent quaking aspen (Populus tremuloides Michx.), subalpine fir (Abies lasiocarpa (Hook.) Nutt.), and Engelmann spruce (Picea engelmanii Parry ex Engelm.) -subalpine fir dominated communities. Selected vegetal characteristics of each of the 16 investigated stands are summarized in Table 1.

Thirty-two macro-plots were sampled between mid-July and mid-September, 1976. Sampling varied in emphasis between community types: eight macro-plots sampled in each of the meadow and aspen, four in the fir, and twelve in the spruce-fir vegetation types. Herbivores were excluded from the macro-plots by either a combination of fencing, sheet metal flashing, and the systemic pesticide Temik ${ }^{\mathrm{R}}$ (Union Carbide Corporation, New York, N.Y.), or by fencing alone. This served to minimize potential structural differences between vegetation types resulting from grazing.

Each macro-plot was sampled twice, just prior to, and approximately 1 month following, peak community production. Herbage was clipped three-dimensionally (Currie et al. 1973) to ground level on five groups of $30 \times 60 \mathrm{~cm}$ quadrats clustered together in aggregates of four, yielding a validation sample size of 20 . The groups were selected to represent the maximum range in standing crop and species composition within each permanent macro-plot. An additional 120 estimated- or metered-only quadrats were randomly selected in each sampling. Clustering of quadrats is not essential to double-sampling but permits easy comparisons and checks on estimations between quadrats (Hutchings and Schmautz 1969).

A Neal Electronics (Burbank, CA) Model 18-2000 Herbage Meter was used to obtain electronic capacitance readings. Dry weight estimation was performed as described by Tadmor et al. 
Table 1. Dominant species and terminal (1977) standing crops $\left(\mathrm{g} / \mathrm{m}^{2}\right)$ within established macro-plots in four vegetation types.

\begin{tabular}{|c|c|c|c|c|}
\hline Macro-plot number & Vegetation type & Dominant herbaceous species & Common name ${ }^{1}$ & $\begin{array}{l}\text { Terminal standing } \\
\text { crop }\left(\mathrm{g} / \mathrm{m}^{2}\right)\end{array}$ \\
\hline 1 & Meadow & Madia glomerata Hook. & Cluster tarweed & 55.01 \\
\hline 2 & Meadow & Bromus carinatus Hook. \& Arn. & Mountain brome & 119.12 \\
\hline 3 & Meadow & Eriogonum heracleoides Nutt. & Wyeth eriogonum & 59.68 \\
\hline 4 & Meadow & Potentilla arguta Pursh & Cinquefoil & 62.04 \\
\hline 5 & Aspen & Bromus carinatus Hook. \& Arn. & Mountain brome & 43.11 \\
\hline 6 & Aspen & Erigeron speciosus (Lindl.) D.C. & Oregon fleabane & 38.78 \\
\hline 7 & Aspen & Bromus carinatus Hook. \& Arn. & Mountain brome & 24.66 \\
\hline 8 & Aspen & Aster integrifolius Nutt. & Thickstem aster & 49.68 \\
\hline 9 & Fir & Hieracium scouleri Hook. & Woollyweed & 11.70 \\
\hline 10 & Fir & Rudbeckia occidentalis Nutt. & Western coneflower & 31.07 \\
\hline 11 & Spruce-Fir & Hieracium scouleri Hook. & Woollyweed & 11.96 \\
\hline 12 & Spruce-Fir & Stellaria jamesiana Torr. & Tuber starwort & 19.96 \\
\hline 13 & Spruce-Fir & Pedicularis racemosa Dougl. & Sickletop pedicularis & 1.73 \\
\hline 14 & Spruce-Fir & Pedicularis racemosa Doug. & Sickletop pedicularis & 6.55 \\
\hline 15 & Spruce-Fir & Stellaria jamesiana Torr. & Tuber starwort & 4.13 \\
\hline 16 & Spruce-Fir & Stellaria jamesiana Torr. & Tuber starwort & 1.67 \\
\hline
\end{tabular}

${ }^{1}$ Common names follow Plummer et al. (1977).

(1975). Yield estimates were made in grams of oven-dry weight per quadrat. We modified the relative weight estimation technique of Hutchings and Schmautz (1969) to permit the use of a single regression for the entire macro-plot. They suggested the use of a central (validation) quadrat to which four surrounding quadrats are then compared. In this study, the quadrat with the greatest standing crop was set to 100 and all other quadrats in the macroplot were then assigned a percentage of this maximum standing crop. Canopy cover estimations were based on Daubenmire (1959), where the canopy of herbaceous plants is visually forced together in a nonoverlapping fashion. The percentage cover is the relative area of the quadrat occupied by the vegetal canopy.

The field workers had no previous experience in estimating dry weights, relative weights, or foliage cover prior to this study. To eliminate interactions between workers, the same person was responsible for a technique throughout the study. No training period or checks on estimates were undertaken since we wished to test the hypotheses that (1) no improvement results from experience with a technique and (2) consistency is the result of natural skill in estimating rather than from training (cf. Tadmor et al. 1975).

Concurrent studies at the site provided data on biological and environmental factors considered potentially important in affecting the performance of the estimation techniques. A total of 24 factors were selected as independent variables for stepwise additive multiple regression analysis (Table 2). Coefficients of determination $\left(r^{2}\right)$ for each double-sampling regression were used as dependent variable observations. The use of residual mean square error as an additional dependent variable in comparing estimator performance (Black et al. 1969; Currie et al. 1973; Neal et al. 1976) was not considered appropriate since it would be meaningful only in comparing estimations of the same populations. Furthermore, the coefficient of determination is the single most important variable used in calculating required sample sizes for double sampling (Tenebein 1971, 1974).

Herbaceous standing crop and litter independent variables are expressed as grams of oven-dried $\left(70^{\circ} \mathrm{C}\right.$ for $24 \mathrm{hr}$ ) phytomass. Litter is defined to include both standing dead and downed herbaceous necromass. The litter was collected in two categories determined by current or prior growing season origin. Various combinations of phytomass and necromass were investigated in the regression analysis as shown in Table 2 .

Diversity indices were calculated to include only those species with standing crops $\geq 0.01 \mathrm{~g}$ (i.e. easily discernable species). Percentage dissimilarity (Odum 1950) represents the mean percentage of total biomass in the dominant species (Pielou 1975). Shannon-Wiener's H' (Shannon and Weaver 1949) is a common index of diversity which incorporates both richness and equitability (Peet 1974). A parallel study of the forest vegetation by Williams (1977) provided data on tree basal areas, deadfall and tree leaf litter weights. Variances (or standard deviations) of most of the independent variables were included as additional variables in the regression analysis.

Estimated required samples sizes for detecting differences in clipped sample means of $\pm 10 \%$ ( $P \leq 0.1)$ Mendenhall et al. 1971) are based on data obtained from an extensive sampling of the same macro-plots in 1977. Multiple comparisons of estimator performance were computed using analysis of variance (ANOVA) fol-

Table 2. Independent variables used in multiple regression analysis of double-sampling estimator performance.

\begin{tabular}{|c|c|}
\hline No. Abbr. & Description \\
\hline \multicolumn{2}{|c|}{ Herbaceous standing crop $\left(\mathrm{g} / \mathrm{m}^{2}\right)$} \\
\hline $1 \overline{\mathrm{xSC}}$ & Mean standing crop \\
\hline $2 \mathrm{~s}^{2} \mathrm{SC}$ & Variance in standing crop \\
\hline $3 \bar{x} \mathrm{Cv}$ & Mean percentage foliage cover \\
\hline $4 \mathrm{~s}^{2} \mathrm{Cv}$ & Variance in percentage foliage cover \\
\hline \multicolumn{2}{|c|}{ Herbaceous litter $\left(\mathrm{g} / \mathrm{m}^{2}\right)$} \\
\hline $5 \overline{\mathrm{x} C L}$ & Mean current year's litter \\
\hline $6 \mathrm{~s}^{2} \mathrm{CL}$ & Variance in current year's litter \\
\hline $7 \bar{x} P L$ & Mean previous years' litter \\
\hline $8 \mathrm{~s}^{2} \mathrm{PL}$ & Variance in previous years' litter \\
\hline $9 \bar{x} T L$ & Mean total litte \\
\hline $10 \mathrm{~s}^{2} \mathrm{TL}$ & Variance in total litter \\
\hline $11 \bar{x}$ TOM & Mean total organic matter \\
\hline $12 \mathrm{~s}^{2} \mathrm{TOM}$ & Variance in total organic matter \\
\hline \multicolumn{2}{|l|}{$13 \underline{\bar{x}} \mathrm{CL} /$} \\
\hline$\overline{\mathbf{x}} \mathrm{TOM}$ & $\begin{array}{l}\text { Ratio of mean current year's litter to mean total organic } \\
\text { matter }\end{array}$ \\
\hline $14 \overline{\mathrm{x} T L /}$ & \\
\hline $15 \frac{\bar{x} \text { TOM }}{\mathrm{x} C L / S C}$ & $\begin{array}{l}\text { Ratio of mean total litter to mean total organic matter } \\
\text { Ratio of mean current year's litter to mean standing cro }\end{array}$ \\
\hline
\end{tabular}

Herbaceous diversity

$16 \overline{\mathrm{x}} \#$ SPP Mean number of species per quadrat

17 s\#SSP Standard deviation in number of species per quadrat

$18 \mathrm{H}^{\prime} \quad$ Shannon-Wiener diversity $\left(\log _{10}\right)$

$19 \mathrm{~J}^{\prime} \quad$ Equitability $\left(\log _{10}\right)$

$20 \%$ Diss Mean percentage dissimilarity

Woody components

21 Df Deadfall $(\mathrm{kg} / \mathrm{ha})$

$22 \bar{x} L L \quad$ Mean tree leaf litter $(\mathrm{kg} / \mathrm{ha})$

23 sLL Standard deviation of tree leaf litter $(\mathrm{kg} / \mathrm{ha})$

24 BA Tree Basal area $\left(\right.$ in $\left.^{2}\right)$ 
lowed by an LSD-test when the ANOVA was significant $(P \leq 0.1)$ (Snedecor and Cochran 1967). Double-sampling statistics followed Cochran (1977), with validation and largescale sample sizes calculated for the fixed variance model by the procedure of Tenebein (1971, 1974). Coefficients of variation for required sampling times were tested for significant differences $(P \leq 0.1)$ by log transformation of the sampling time in minutes (Lewontin 1966), calculating a preliminary ANOVA using the variance of the log sampling time, and using the LSD-test to detect treatment differences.

\section{Results and Conclusions}

\section{Regression Analysis}

Results from the regression study indicated that the estimation techniques were significantly correlated $(P \leq 0.2)$ with many of the 24 investigated variables (Tables $3 \mathrm{a}$ and $3 b)$. When these were evaluated by stepwise regression, however, only three partial correlations remained significant. This indicates that extensive intercorrelations exist among the variables and that stepwise regression procedures are needed to determine which variables account for the greatest variance in the double-sampling correlations.

The most significant variable detected by the stepwise regression analysis as affecting electronic capacitance metering is the variation in the mean number of species per quadrat. Moderate variation in numbers of species is optimum for meter performance, while low or high variations have a standard deviation of approximately 1.7 species per quadrat. These conditions were generally found on the meadow sites. Species variability in the aspen type was much higher, ranging up to a standard deviation of 3.1 species per quadrat. Coniferous understory generally had a low variability in species, with a standard deviation of about 0.8 species per quadrat. Poorer estimates of herbaceous standing crop were obtained with an electronic capacitance meter in the latter two types.

The mean and variance of the percent foliage cover per quadrat also influenced meter performance. When either of these variables increased, meter performance improved. This generally occurred in Potentilla or Eriogonumdominated meadows and on the fir plots.

Currie et al. (1973) and Neal et al. (1976) have reported that large interquadrat differences in species composition result in increased metering error. Our results additionally show that as a monotypic condition is approached, this error also increases. This low variation in number of species was characteristic not only of coniferous understory, but also in Madia glomerata-dominated meadows.

The apparent illogical performance of the meter in sampling situations where there are moderate diversity and large variances in foliage cover between quadrats, can largely be explained by the limitations of regression analysis in doublesampling. Both of these situations can result in a greater scattering of the $\{x, y\}$ values in the double-sampling regression, tending to increase the coefficient of determination over that which would be obtained if the $\{x, y\}$ values were clumped and the relationship less defined. This response of a double-sampling regression to data variability was the single most important phenomenon affecting the performance of all four estimation techniques. Workers should be aware that purposely selecting the small-scale (validation) sample in this technique, as recommended by Cochran (1963) and Haydock and Shaw (1975), can bias the resulting statistics when the small-scale samples does not reflect the true varia- tion in the large-scale (metered-only) sample.

The greater importance of cover over dry matter weight in affecting meter performance cannot be precisely explained without the measurement of internal plant moisture. Cover was generally more correlated to internal moisture (as measured by electronic capacitance) than to dry matter weight. It is mainly water which determines meter readings since, at $20^{\circ} \mathrm{C}$, water has a dielectric constant (capacitance) 32 times greater than that of dry plant fiber or cellulose (Edlefsen 1933). This would suggest that quadrats for the clipped validation sample should be selected for the range in internal moisture over a macro-plot, rather than dry matter.

Additional factors were observed to bias the capacitance meter, but could not be quantified for regression analysis. Moisture sinks, such as soil (Kreil and Matschke 1968; Jones and Haydock 1970), litter, and pocket gopher mounds are heterogenous within macro-plots and may strongly bias meter readings. Despite calibrating the meter on bare ground, non-vegetated quadrats commonly showed differences in meter readings of \pm 3 capacitance units (approximately $\pm 8 \mathrm{~g} / \mathrm{m}^{2}$ ). This was due to variations in soil and litter moisture and is supported by a significant negative correlation between meter performance and increases in the variability and amount of tree leaf litter (Table $3 a$ ). Since $43 \%$ of the sampled quadrats had less than $3 \mathrm{~g} / \mathrm{m}^{2}$ of standing crop, this bias was considered appreciable.

It was preferable to estimate meter readings on quadrats where the readings are highly questionable or impossible to obtain. The latter situation is often encountered when obstructions such as rocks, trees, or deadfall occur in a random sampling of quadrats. Meter readings were not estimated on clipped quadrats. Up to $41 \%$ of the quadrats in metered-only samples, however, required estimation in densely wooded stands.

A three variable regression model predicting meter performance accounted for $73 \%$ of the variance in doublesampling correlations. It required measurement in the field of only two variables: number of species per quadrat and percentage foliage cover per quadrat.

The three most significant variables affecting relative weight estimation are the variance in the number of species per quadrat, Shannon-Wiener diversity, and the variance in percent foliage cover (Table 3a). Response to variance in species numbers is similar to capacitance metering with highest estimator performance occurring with moderate standard deviations (approximately 1.7 species per quadrat). Relative weight estimation performance is less affected by lower and higher standard deviations than is capacitance metering. High Shannon-Wiener diversity and variance in cover improved the performance of this estimator. Hence, optimum estimator performance is observed on macro-plots with large variations in foliage cover and a large number of species having moderate interquadrat variability.

It was observed that relative weight estimation is easier to perform when quadrats are well vegetated and have a stable species composition. On depauperate macro-plots, estimation was weighted towards differences in density and cover between quadrats. On macro-plots which were heterogeneous in species composition, difficulty was encountered in visually comparing the phytomass of dissimilar quadrats. Visual integration of height, density, cover, etc., had to be more strongly weighted for such factors as weight to surface area and green to dry weight ratios among the different 
Table 3a. Simple $(r)$ and partial $(R)$ correlation coeficients for 24 independent variables potentially biasing electronic capacitance metering or relative weight estimators of herbaceous standing crop. Correlations reflect the influence of these independent variables on variations in double-sampling correlations for the two estimators.

\begin{tabular}{|c|c|c|c|c|c|c|c|c|c|}
\hline \multirow[b]{2}{*}{ Variable ${ }^{1}$} & \multicolumn{5}{|c|}{ Electronic capacitance metering } & \multicolumn{4}{|c|}{ Relative weight estimation } \\
\hline & $\mathrm{n}^{2}$ & $r$ & P level ${ }^{3}$ & $\boldsymbol{R}$ & $P$ level $^{4}$ & $r$ & $P$ level & $R$ & $P$ level \\
\hline $\mathrm{xSC}$ & 20 & .393 & .03 & & & $.401^{5}$ & .04 & & \\
\hline $\mathbf{s}^{2} \mathrm{SC}$ & 30 & .477 & .008 & & & $.476^{5}$ & .01 & & \\
\hline $\mathrm{xCv}$ & 31 & .409 & .02 & .336 & .02 & -.184 & $>.20$ & & \\
\hline $\mathbf{s}^{2} \mathrm{Cv}$ & 31 & .454 & .01 & .543 & .01 & .368 & .04 & .355 & .08 \\
\hline $\mathrm{xCL}$ & 31 & .318 & .08 & & & -.195 & $>.20$ & & \\
\hline$s^{2} C L$ & 31 & -.137 & $>.20$ & & & -.188 & $>.20$ & & \\
\hline xPL & 25 & .318 & .13 & & & -.237 & $>.20$ & & \\
\hline $\mathbf{s}^{2} \mathbf{P L}$ & 25 & .436 & .03 & & & -.219 & $>.20$ & & \\
\hline$x T L$ & 25 & .364 & .06 & & & -.144 & $>.20$ & & \\
\hline$s^{2} T L$ & 25 & .397 & .05 & -.191 & $>.20$ & & & & \\
\hline xTOM & 30 & .374 & .04 & & & $.434^{s}$ & .03 & & \\
\hline $\mathrm{s}^{2}$ TOM & 30 & .389 & .04 & & & .188 & $>.20$ & & \\
\hline xCL/xTOM & 25 & -.202 & $>.20$ & & & .380 & .06 & & \\
\hline xTL/xTOM & 25 & .183 & $>.20$ & & & .287 & .17 & & \\
\hline $\mathrm{xCL} / \mathrm{xSC}$ & 30 & -.412 & .03 & & & -.124 & $>.20$ & -.190 & .13 \\
\hline X\#SPP & 25 & .375 & .05 & & & -.275 & .19 & & \\
\hline s\#SPP & 25 & $.523^{5}$ & .005 & $.566^{5}$ & .004 & $.532^{5}$ & .002 & $.545^{5}$ & .04 \\
\hline $\mathrm{H}^{\prime}$ & 25 & $.469^{5}$ & .02 & & & -.291 & .16 & -.335 & .11 \\
\hline $\mathbf{J}^{\prime}$ & 25 & -.288 & .17 & & & .303 & .15 & .321 & .06 \\
\hline$\%$ Diss & 25 & -.132 & $>.20$ & & & .300 & .15 & .021 & .00 \\
\hline Df & 31 & .353 & .05 & & & .408 & .02 & & \\
\hline$x L L$ & 31 & -.440 & .01 & & & .275 & .14 & & \\
\hline sLL & 31 & -.423 & .02 & & & .106 & $>.20$ & .239 & .07 \\
\hline BA & 31 & -.434 & .02 & & & .359 & .05 & & .01 \\
\hline
\end{tabular}

'See abbreviations of variables in Table 1 .

$2 n=25$ for all partial correlation coefficients.

${ }^{3}$ Probability that the regression coefficient $\left(\beta_{0}\right)$ equals zero.

4 Significant $(P \leq .20)$ variables only.

sSignificant quadratic relationship $(P \leq .05)$ that the regression coefficient $\left(\beta_{1}\right)$ equals zero).

Table 3b. Simple (r) and partial $(R)$ correlation coefficients for 24 independent variables potentially biasing dry weight or foliage cover estimators of herbaceous standing crop. Correlations reflect the influence of these independent variables on variations in double-sampling correlations for the two estimators.

\begin{tabular}{|c|c|c|c|c|c|c|c|c|c|}
\hline \multirow[b]{2}{*}{ Variable' } & \multicolumn{5}{|c|}{ Dry weight estimation } & \multicolumn{4}{|c|}{ Canopy cover estimation } \\
\hline & $\mathrm{n}^{2}$ & $r$ & $P$ level $^{3}$ & $R$ & $P$ level $^{4}$ & $r$ & $P$ level & $R$ & $P$ level \\
\hline $\mathrm{xSC}$ & 30 & -.242 & .20 & & & $.445^{5}$ & .02 & .228 & .001 \\
\hline $\mathrm{s}^{2} \mathrm{SC}$ & 30 & .418 & .04 & .251 & .12 & -.301 & .11 & -.247 & .05 \\
\hline $\mathrm{xCv}$ & 31 & -.190 & $>.20$ & -.182 & .10 & -.448 & .01 & -.100 & .08 \\
\hline $\mathbf{s}^{2} \mathrm{Cv}$ & 31 & $.560^{5}$ & .001 & .541 & .04 & .214 & $>.20$ & & \\
\hline $\mathrm{xCL}$ & 31 & .141 & $>.20$ & & & -.433 & .02 & & \\
\hline $\mathrm{s}^{2} \mathrm{CL}$ & 31 & -.090 & $>.20$ & & & -.381 & .04 & -.394 & .02 \\
\hline $\mathbf{x}:$ & 25 & -.278 & .18 & -.352 & .05 & -.468 & .02 & & \\
\hline $\mathbf{s}^{2} \mathbf{P L}$ & 25 & .221 & $>.20$ & & & $.479^{5}$ & .02 & .395 & .01 \\
\hline xTL & 25 & -.090 & $>.20$ & & & -.501 & .01 & נדנב. & .01 \\
\hline$s^{2} T L$ & 25 & .169 & $>.20$ & & & $.508^{5}$ & .01 & .329 & .003 \\
\hline xTOM & 30 & -.230 & $>.20$ & & & -.446 & .01 & & \\
\hline $\mathrm{s}^{2}$ TOM & 30 & .174 & .20 & & & $.537^{5}$ & .002 & & \\
\hline xCL/xTOM & 25 & .230 & $>.20$ & & $\cdot$ & $.619^{5}$ & $>.001$ & & \\
\hline xTL/xTOM & 25 & .267 & .20 & & & -.645 & $>.001$ & -645 & .001 \\
\hline $\mathrm{xCL} / \mathrm{xSC}$ & 30 & -.098 & $>.20$ & & & $.541^{5}$ & .003 & & \\
\hline $\mathrm{x} \#$ SPP & 25 & -.245 & $>.20$ & & & -.418 & .04 & & \\
\hline s\#SPP & 25 & -.394 & .05 & -.394 & .05 & -.394 & .05 & -.218 & .18 \\
\hline $\mathbf{H}^{\prime}$ & 25 & .223 & $>.20$ & & & -.341 & .09 & & \\
\hline $\mathbf{J}^{\prime}$ & 25 & .143 & $>.20$ & & & .336 & .10 & & \\
\hline$\%$ Diss & 25 & .144 & $>.20$ & & & .491 & .01 & & \\
\hline Df & 31 & .418 & .02 & .207 & .17 & .375 & .04 & & \\
\hline$x L L$ & 31 & .170 & $>.20$ & .197 & .17 & .341 & .06 & & \\
\hline sLL & 31 & -.054 & $>.20$ & & & .215 & $>.20$ & & \\
\hline BA & 31 & .298 & .10 & .321 & .04 & .326 & .08 & & \\
\hline
\end{tabular}

'See abbreviations of variables in Table 1 .

$2_{n}=25$ for all partial correlation coefficicnts.

${ }^{3}$ Probability that the regression coefficient $\left(\beta_{0}\right)$ equals zero.

${ }^{4}$ Significant $(P \leq .20)$ variables only.

sSignificant quadratic relationship $(P \leq .05)$ that the regression coefficient $\left(\beta_{1}\right)$ equals zero). 
species.

Dry weight estimation is most significantly affected by variance in foliage cover, variance in number of species per quadrat, and the mean weight of the previous years' litter (Table $3 b)$. In comparison to relative weight estimation, accurate dry weight estimation requires high interquadrat variation in species composition and cover and low amounts of litter from previous years. Tadmor et al. (1975) concluded that fairly homogeneous species composition was required for successful dry weight estimations. We conclude that high variation among quadrats compensates for the inaccuracies in dry weight estimation with untrained workers. It is also an artifact of the regression analysis as previously discussed. The importance of litter is probably due to the relatively greater percentage of difficult-to-estimate grasses and tall forbs, where previous year's litter is abundant (e.g. meadows and aspen), versus the higher percentage of easy to estimate broad-leaved forbs in the coniferous understory, where previous year's litter was low.

The relative and dry weight estimation techniques were found to be less affected by the investigated factors than metering. The best three variable models accounted for $59 \%$ of the variance in relative weight correlations and $66 \%$ in dry weight correlations.

No significant $(P \leq .20)$ trends in double-sampling correlations with workers experience were detected for either relative or dry weight estimations. The results would tend to support the conclusion of Tadmor et al. (1975) that naturally skilled persons can successfully make dry weight estimations without training. Some of this skill was possibly gained through weighing oven dry herbage in the laboratory and previous use of an electronic capacitance meter. This is thought to improve estimation ability as the worker becomes more adept at compensating for previously observed differences in moisture content, weight to area ratios, etc., as they apply to dry weight. Training, rather than simply experience, is needed to achieve consistent estimates under a variety of conditions. Training in relative weight estimation appears to be less crucial than has been suggested by previous workers (Hutchings and Schmautz 1969; Haydock and Shaw 1975).

Any training scheme should emphasize achieving linearity in the range of estimations (Campbell and Arnold 1973), rather than simply a high estimator to dry weight correlation. Inexact, though consistenlty biased estimations are corrected in the regression calibration. But transformation of nonlinear estimations is not possible using the doublesampling statistics of Cochran (1977). In situations where the vegetation is harvested at periodic intervals over the growing season, retraining would be necessary for major changes in phenology and species composition. The additional cost of training would tend to reduce the benefits of double-sampling procedure over that of clipping. It was found useful to examine photographs of previously estimated quadrats, where actual values were known, to become refamiliarized with estimating under a particular vegetal condition.

The relationship of canopy cover to standing crop is strongly biased by herbaceous litter. A three variable model incorporating (1) the ratio of total litter to total organic matter, (2) the variance in previous years' litter, and (3) the variance in current year's litter (Table 3b), accounted for $73 \%$ of the variance in double-sampling correlations. Where litter amounts were low, double-sampling correlations were exceptionally high. This generally occurred in spruce-fir plots where perennial forbs were dominant. In meadows and aspen plots where grasses and annual were abundant and/or grazing was evident, canopy cover was a much less consistent estimator. The high partial correlation of -.645 for the ratio of total litter to total organic matter versus foliage cover estimation ${ }^{2}$ reflects the difficulty we had in using cover, as a standing crop estimator late in the growing season when live and dead plant components were difficult to differentiate.

It would be expected that the addition of a vegetative height term would improve double-sampling correlations (Pasto et al. 1975, Evans and Jones 1958). Height and cover must be combined into a single variable such as volume (Alexander et al. 1962), since double-sampling is a bivariate statistical technique. Whether volume estimates or objective measurements of height and cover are cost efficient, in the sense of the discussion which follows, needs further research.

\section{Cost Analysis}

The approach to the question of which estimator is superior in a given vegetation type was to compare the costs, in time, of sampling for equal precision with any of the four estimators. The total sampling cost is a sum of the cost for the large sample of estimated-only quadrats plus the small sample of estimated and clipped quadrats. A required sample size for both was estimated knowing (1) the sample size required to meet a given level of precision if one was to clip only, (2) the correlation between an estimator and herbage dry weight, and (3) the ratio in costs between an estimated and clipped quadrat (Tenebein 1971, 1974).

The average time required for metering or estimating and clipping a quadrat in the four vegetation types is given in Table 4. In general, it requires from 16 to 70 times as long to clip a quadrat as to estimate it. The amount of time for any operation is proportional to the standing crop of herbage

Table 4. Average sampling times per quadrat (in minutes) for electronic capacitance metering (MTR), relative weight estimation (RWE), dry weight estimation (DWE), and canopy cover estimation (CCE), in four vegetation types.

Time

Vegetation type $\quad$ Operation (minutes)

and estimation techique Metering/Estimating Clipping

Meadow

$\begin{array}{lll}\text { MTR } & .75 & 35\end{array}$

RWE/DWE

$\mathrm{CCE}$

.70

.50

Aspen

MTR

RWE/DWE

$\mathrm{CCE}$

1.05

.66

.54

ir

MTR

RWE/DWE

CCE

1.25

.56

.40

17
17

Spruce-Fir

MTR

RWE/DWE

CCE

1.05

.25

.25
35
35
35

35

17

35

35

35

17

4 
Table 5. Comparison of mean coefficients of determiniations ( \pm standard errors) obtained with four double-sampling estimators of subalpine herbaceous standing crop.

\begin{tabular}{lccccc}
\hline \hline \multirow{2}{*}{ type } & \multicolumn{3}{c}{ Vegetation } & \multicolumn{2}{c}{ Estimator } \\
\cline { 2 - 6 } Meadow & $\mathrm{n}$ & $\mathrm{MTR}^{1}$ & $\mathrm{RWE}^{2}$ & $\mathrm{DWE}^{3}$ & $\mathrm{CCE}^{4}$ \\
\hline \multirow{2}{*}{ Aspen } & 8 & $.753 \mathrm{a}^{5}$ & $.687 \mathrm{a}$ & $.701 \mathrm{a}$ & $.524 \mathrm{a}$ \\
& & \pm .047 & \pm .083 & \pm .075 & \pm .100 \\
Fir & 8 & $.433 \mathrm{a}$ & $.580 \mathrm{a}$ & $.542 \mathrm{a}$ & $.490 \mathrm{a}$ \\
& & \pm .083 & \pm .092 & \pm .100 & \pm .087 \\
Spruce-fir & 4 & $.705 \mathrm{a}$ & $.881 \mathrm{a}$ & $.884 \mathrm{a}$ & $.536 \mathrm{a}$ \\
& & \pm .057 & \pm .011 & \pm .012 & \pm .123 \\
& 12 & $.535 \mathrm{a}$ & $.788 \mathrm{~b}$ & $.740 \mathrm{~b}$ & $.786 \mathrm{~b}$ \\
& & \pm .087 & \pm .060 & \pm .080 & \pm .009 \\
\hline
\end{tabular}

'Electronic capacitance metering.

${ }^{2}$ Relative weight estimation.

${ }^{3}$ Dry weight estimation.

${ }^{4}$ Canopy cover estimation.

${ }^{5}$ Different lower case letters denote significant differences $(P \leq 0.1)$ between means within vegetation types

present and the density of the vegetation. Included in the time requirement are locating and marking quadrats, preparing sample bags for each quadrat, clipping off vegetation extending outside the capacitance meter field, and other operations directly related to sampling.

A multiple comparison of the mean coefficient of determinations $\left(r^{2}\right)$ obtained in four vegetation types (Table 5) shows that a significant difference between estimators was detected for the spruce-fir type only. Here electronic capac-

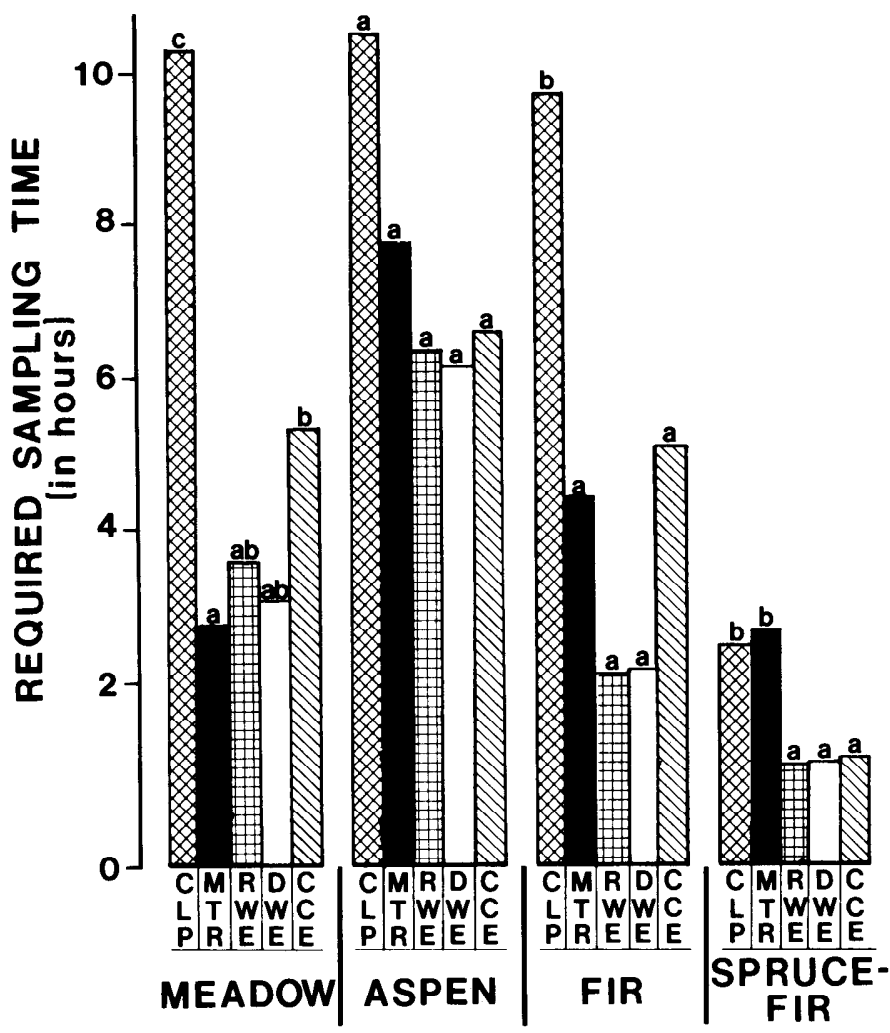

Fig. 1. Comparison of total sampling costs (in worker hours) for clipping (CLP) only, and for double-sampling with electronic capacitance metering $(M T R)$, relative weight estimation ( $R W E)$, dry weight estimation $(D W E)$, and canopy cover estimation (CCE) within four subalpine vegetation types. Costs based on sampling to detect differences between means of $\pm 10 \%$ with a probability level of $\leq 0.1$. Different lower case letters indicate significant differences $(\mathrm{P} \leq 0.1)$ between means within each vegetaion type. itance metering was significantly less precise than the other estimators. This trend is apparent in the fir and aspen types, also, reflecting the general difficulty of metering in understory vegetation. Canopy cover was apparently a poorer estimator than the others in the meadow and aspen types. The aspen plots were difficult to sample precisely with any technique.

A comparison of the average sampling costs for clipping only against the costs for sampling with each of the four estimators (Fig. 1), shows that clipping is more expensive than using a double-sampling estimator to achieve the same level of precision in sampling. These differences range in expense from 1.3 times greater in aspen, to 4 times greater in the fir type. Maximum gains in sampling time were achieved when the double-sampling estimator was best suited for the vegetation type being sampled.

Significant differences $(P \leq 0.1)$ were detected between estimators in the meadow, fir, and spruce-fir vegetation types (Figure 1). A significant difference does not imply practical significance (Brewer 1975). To be practically different, we required an estimator to permit at least a $25 \%$ reduction in sampling cost in addition to having statistical significance. Under this criterion, clipping was practically more expensive than any double-sampling technique in all vegetation types except spruce-fir, where metering was also more expensive. Among double-sampling estimators, canopy cover estimation was practially more expensive than metering and relative and dry weight estimations in meadows. No other practical differences were detected.

Besides permitting either a larger sample size at equal costs, or the same sample size at a lower sampling cost, a useful double-sampling estimator should be reliable over the range of vegetal and environmental conditions encountered in a given vegetation type. The coefficient of variation in sampling costs was considered to be an effective index of "reliability." A lower coefficient of variation is indicative of stability in sampling costs over a wide range of conditions. Table 6 gives the coefficients of variation for the five sampling techniques in each of the four vegetation types. Electronic capacitance metering was the most reliable technique in meadows, clipping in aspen, relative weight estimation in fir, and dry weight estimation in spruce-fir vegetation types. Averaged across vegetation types, metering and relative

Table 6. Comparison of coefficients of variatn ( \pm standard errors) in field time required for sampling sub-alpine herbaceous standing crop using five different techniques.

\begin{tabular}{|c|c|c|c|c|c|c|}
\hline $\begin{array}{l}\text { Vegetation } \\
\text { type }\end{array}$ & $\mathrm{n}$ & $\begin{array}{c}\text { CLP' } \\
(\%)\end{array}$ & $\begin{array}{c}\text { MTR }^{2} \\
(\%)\end{array}$ & $\begin{array}{c}\mathrm{RWE}^{3} \\
(\%)\end{array}$ & $\begin{array}{c}\mathrm{DWE}^{4} \\
(\%)\end{array}$ & $\begin{array}{l}\mathrm{CCE}^{4} \\
(\%)\end{array}$ \\
\hline Meadow & 8 & $\begin{aligned} & 87 a^{6} \\
\pm & 34\end{aligned}$ & $\begin{aligned} & 51 b \\
\pm & 16\end{aligned}$ & $\begin{aligned} & 58 b \\
\pm & 19\end{aligned}$ & $\begin{aligned} & 58 \mathrm{~b} \\
\pm & 19\end{aligned}$ & $\begin{array}{r}73 \mathrm{ab} \\
\pm 26\end{array}$ \\
\hline Aspen & 8 & $\begin{array}{r}45 a \\
\pm 13\end{array}$ & $\begin{array}{c}\quad 66 a \\
\pm 23\end{array}$ & $\begin{array}{r}69 a \\
+24\end{array}$ & $\begin{array}{r}75 a \\
\pm 27\end{array}$ & $\begin{array}{r}74 a \\
\pm 27\end{array}$ \\
\hline Fir & 4 & $\begin{array}{r}67 a \\
\pm 33\end{array}$ & $\begin{array}{r}56 a \\
\pm 25\end{array}$ & $\begin{array}{r}52 a \\
\pm 23\end{array}$ & $\begin{array}{c}69 a \\
\pm 34\end{array}$ & $\begin{array}{r}74 a \\
\pm 38\end{array}$ \\
\hline Spruce-Fir & 12 & $\begin{array}{r}62 a \\
\pm 17\end{array}$ & $\begin{array}{r}62 a \\
\pm 17\end{array}$ & $\begin{array}{r}62 \mathrm{a} \\
\pm 17\end{array}$ & $\begin{array}{r}59 a \\
\pm 16\end{array}$ & $\begin{array}{l}63 \mathrm{a} \\
\pm 17\end{array}$ \\
\hline
\end{tabular}

'Clipping.

${ }^{2}$ Electronic capacitance metering.

${ }^{3}$ Relative weight estimation.

${ }^{4}$ Dry weight estimation.

${ }^{5}$ Canopy cover estimation.

${ }^{6}$ Different lower case letters denote signicant differences $(P \leq 0.1)$ between coefficients of determination within vegetation types. 
weight estimation were the most reliable estimators for subalpine vegetation as a whole. Dry weight estimation was equally as reliable as clipping, and canopy coverage was the least reliable method use.

\section{Recommendations}

Selection of an appropriate double-sampling estimator for sampling subalpine herbage production will partly depend on vegetation type(s) to be sampled. Ideally, selecting the most appropriate technique for each vegetation type will result in the lowest sampling cost (or highest statistical precision). Practically, however, most workers choose one technique which offers reliability and simplicity as well as precision and low cost.

Clipping is the least efficient technique for herbage sampling all but the aspen vegetation type. A significant difference between estimators in aspen understory vegetation was not detected. However, a practical difference between clipping and double-sampling is to be expected here.

Electronic capacitance metering appears best suited for well-vegetated meadows with little soil disturbance and low rockiness. It would be a second choice for sampling aspen understory where the estimation of some quadrats may be required due to trees. It is not recommended for use in coniferous understory where leaf litter results in erratic performance. Electronic capacitance metering was highly biased by the investigated factors. Balancing the increased precision of metering in meadow vegetation, the worker must consider the high initial cost of the meter, the potential fallibility of its electronic circuitry, and its restricted portability.

Relative weight estimation is a relatively simple technique which appeared to be reliable and precise in all four vegetation types studied. It was the least biased by any of the vegetal and environmental factors investigated. Relative weight estimation requires the least mental arithmetic (hence, less fatigue) of the three subjective estimators.

Dry weight estimation was nearly equal to relative weight estimation in precision and cost. It was slightly morc biased by vegetal and environmental factors and requires more mental calculations. It likely requires more talent to use correctly than relative weight estimation.

Canopy cover estimation is a straight forward and nearly objective technique which appears suitable in dense coniferous forest with sparse understory vegetation. Its uses should probably be limited to stands where little or no grasses or tall forbs are present, as they have a very different cover to weight ratio than do low-statured forbs. Canopy cover estimation was strongly biased by the investigated factors and was not as reliable as the other estimators.

\section{Literature Cited}

Alock, M.B., and J.V. Lovett. 1967. The electronic measurement of the yield of growing pasture. I. A statistical assessment. J. Agr. Sci., Camb. 68: 27-38.

Alexander, C.W., J.T. Sullivan, and D.E. McCloud. 1962. A method for estimating forage yields. Agron. J. 54: 468-469.

Black, H.L., R.E. Alder, and B.G. Gibbs. 1969. An evaluation of an electronic instrument for pasture yield estimation. 2. Use with doublesampling for regression estimation. J. British Grassl. Soc. 24: 168-172.

Brewer, J.K. 1953. Reporting P. values. Amer. Stat. 29: 171.

Bryant, A.M., O.F. Parker, M.A.S. Cook, and M.J. Taylor. 1971. An evaluation of the performance of the capacitance meter for estimating the yield of dairy pasture. Proc. New Zealand Grassl. Ass. 33: 839-89. Camphell, N.A., and G.W. Arnold. 1973. The visual assessment of pasture yield. Austr. J. Exp. Agr. Anim. Husb. 13: 263-267.

Cochran, W.G. 1963. Sampling techniques. 2nd ed. Wiley, New York 413 p.

Cochran, W.G. 1977. Sampling techniques. 3rd ed. Wiley, New York. 428 p.

Currie, P.O., M.J. Morris, and D.L. Neal. 1973. Uses and capabilities of electronic capacitance instruments for estimating standing herbage. Part 2. Sown ranges. J. British Grassl. Soc. 28: 155-160.

Daubenmire, R. 1959. A canopy-coverage method of vegetational analysis. Northw. Sci. 33: 43-64.

Edlefsen, N.E. 1933. A review of results of dielectric methods for measuring moisture present in materials. Agr. Engineer. 14: 243-44.

Evans, R.A., and M.B. Jones. 1958. Plant height times ground cover versus clipped samples for estimating forage production. Agron. J. 50: 504-506.

Green, J.O. 1949. Herbage sampling errors and grazing trials. J. British Grassl. Soc. 4: 11-16.

Haydock, K.P., and N.H. Shaw. 1975. The comparative yield method for estimating dry matter yield of pasture. Aust. J. Exp. Agr. Anim. Husb. 15: 663-670.

Hutchings, S.S., and J.E. Schmautz. 1969. A field test of the relativeweight-estimate method for determining herbage production. J. Range Manage. 2: 408-411.

Jones, R.J., and K.P. Haydock. 1970. Yield estimation of tropical and temperate pasture species using an electronic capacitance meter. J. Agr. Sci., Camb. 75: 27-36.

Jones, R.M., R.L. Sandland, and G.A. Bunch. 1977. Limitations of the electronic capacitance meter in measuring yields of grazed tropical pastures. J. British Grassl. Soc. 32: 105-113.

Kreil, W., and J. Matschke. 1968. Studies on the determination of pasture yields with an electronic measuring instrument. Zeitschrift fur Landeskultur 9: 75-99.

Lewontin, R.C. 1966. On the measurement of relative weight variability. Syst. Zool. 15: 141-142.

Mendenhall, W., L. Ott, and R.L. Scheaffer. 1971. Elementary Survey Sampling. Wadsworth. Belmont, Calif. 247 p.

Michalk, D.L., and P.K. Herbert. 1977. Assessment of four techniques for estimating yield on dryland pastures. Agron. J. 69: 864-868.

Morley, F.H.W., D. Bennett, and K.W. Clark. 1964. The estimation of pasture yield in large grazing experiments. CSIRO Field Sta. Rec. 3: 43.

Neal, D.L., P.O. Currie, and M.J. Morris. 1976. Sampling herbaceous native vegetation with an electronic capacitance instrument. J. Range Manage. 29: 74-77.

Odum, E.P. 1950. Bird populations of the Highlands (North Carolina) Plateau in relation to plant succession and avian invasion. Ecology 31: 587-605.

Pasto, J.K., J.R. Allison, and J.B. Washko. 1957. Ground cover and height of sward as a means of estimating pasture production. Agron. J. 49: 407-409.

Payne, G.F. 1974. Cover-weight relationships. J. Range Manage. 27: 403404.

Peet, R.K. 1974. The measurement of species diversity. Ann. Rev. Ecol. Syst. 5: 285-307.

Pielou, E.C. 1975. Ecological Diversity. Wiley-Interscience, New York. 165 p.

Plummer, A.P., S.B. Monsen, and R. Stevens. 1977. Intermountain range plant names and symbols. U.S. Dep. Agr., Forest Serv., Gen. Tech. Rep. INT-38, $82 \mathrm{p}$.

Shannon, C.E., and W. Weaver. 1949. The Mathematical Theory of Communication. Univ. Ill. Press, Urbana. 177 p.

Snedecor, G.W., and W.G. Cochran. 1967. Statistical Methods, 6th ed. Iowa State Univ. Press, Ames. 593 p.

Tadmor, N.H., A. Brieghet, I. Noy-Mier, R.W. Benjamin, and E. Eyal. 1975. An evaluation of the calibrated weight-estimate method for measuring production in annual grassland vegetation. J. Range Manage. 28: 65-69.

Tenenbein, A. 1971. A double sampling scheme for estimating from misclassified bionomial data: sample size determination. Biometrics 27 : 935-944.

Tenenbein, A. 1974. Sample size determination for the regression estimate of the mean. Biometrics 30: 709-716.

Williams, S. 1977. Tree leaf biomass, and rates of litter fall, litter accumulation and litter decomposition in three stages of a successional sere in northern Utah. M.S. thesis, Dep. Forestry and Outdoor Recreation, Utah State University, Logan. 114 p. 